\title{
Supporting primary school students' reasoning about motion graphs through physical experiences
}

\author{
Carolien Duijzer $^{1}$ (1) $\cdot$ Marja Van den Heuvel-Panhuizen ${ }^{1,2,3} \cdot$ Michiel Veldhuis $^{1,4} \cdot$ Michiel Doorman $^{2}$
}

Accepted: 12 July 2019 / Published online: 3 September 2019

(c) The Author(s) 2019

\begin{abstract}
Reasoning about graphical representations representing dynamic data (e.g., distance changing over time), including interpreting, creating, changing, combining, and comparing graphs, can be considered a domain-specific operationalization of the general twenty-first century skills of creative, critical thinking and solving problems. This paper addresses the issue of how these 21 st century skills of interpreting and creating graphs can be supported in a six-lesson teaching sequence about graphing motion. In this teaching sequence, we focused on the potential of an embodied learning environment to facilitate the development of primary school students' reasoning about motion graphs by having primary school students (9-11 years) 'walk' graphs in front of a motion sensor to generate distance-time graphs. We asked: How does students' reasoning about graphing motion develop over a six-lesson teaching sequence within an embodied learning environment? Based on the collected data, we examined changes in students' level of reasoning on graph interpretation and graph construction tasks using a repeated measurement design. Additionally, we present two teaching episodes showing instances of how perceptual-motor experiences during the lessons aided students' reasoning about graphical representations of motion. Results show that students went from iconic understanding towards understanding in which they reasoned based on one or two variables when interpreting and constructing graphical representations of motion events. At these higher levels of reasoning these students showed understanding of modelling motion in line with the intended 21 st century skills of generating, refining, and evaluating graphs.
\end{abstract}

Keywords Distance-time graphs $\cdot$ Embodied cognition · Graphing motion · Motion sensor technology

\section{Introduction}

Twenty-first century competences include the need for equipping students with an integrated set of knowledge, skills, and attitudes, for example being creative, innovative,

Electronic supplementary material The online version of this article (https://doi.org/10.1007/s11858-019-01072-6) contains supplementary material, which is available to authorized users.

Carolien Duijzer

a.c.g.duijzer@uu.nl

1 Freudenthal Group, Faculty of Social and Behavioural Sciences, Utrecht University, Heidelberglaan 1, 3584 CS Utrecht, The Netherlands

2 Freudenthal Institute, Faculty of Science, Utrecht University, Utrecht, The Netherlands

3 Nord University, Bodø, Norway

4 iPabo University of Applied Sciences, Amsterdam, The Netherlands and communicative (see the categorization of 21 st century skills on http://www.atc21s.org). Such competences are typical of STEM learning in general, and mathematics learning in particular (English 2016; Honey et al. 2014). The capacity to deal with large amounts of new information through media and technology is becoming increasingly important in today's society. This includes the ability to use graphs to produce, present, and understand complex dynamic information (Binkley et al. 2012), as well as making flexible and creative use of representations. Reasoning about graphical representations, making connections between the variables on the horizontal and vertical axes, such as time and distance, creating graphical representations, critically evaluating data represented in graphs, using graphs to communicate findings to others, and also, making comparisons within and between graphs, are important components of higher-order thinking skills within science and mathematics (e.g., Boote 2014). Promoting students' fluency with graphs, as well as stimulating related higher-order reasoning, can therefore be a fruitful way to incorporate 21 st century skills 
within mathematics classrooms. This is also in line with the framework for robust learning, which suggests that domainspecific learning environments are needed to support students in "becoming knowledgeable, flexible, and resourceful disciplinary thinkers" (Schoenfeld 2016, p. 3). There is general consensus (see, e.g., NCTM 2000) that laying a strong foundation for these higher-order thinking skills should start in primary school and that this also applies to the introduction of graphs (e.g., Friel et al. 2001).

\section{Background of the study}

\subsection{Reasoning about graphical representations}

Similarly to number sense (e.g., Resnick 1989) and symbol sense (Arcavi 1994), students have to acquire a graph sense, which "develops gradually as a result of one's creating graphs and using already designed graphs in a variety of problem contexts that require making sense of data" (Friel et al. 2001, p. 145). Graph sense can be considered as representing a way of thinking, rather than as a specific set of rules and skills that can be transmitted to others (Friel et al. 2001). Such graph sense includes the interpretation or construction of graphs and the ability to distinguish between discrete and continuous representations. It also includes the ability to recognize the meaning and significance of the represented variables, the slope, and the more general visual characteristics of the graph (e.g., Friel et al. 2001; Robutti 2006). In this paper, we focus on graphs representing the bivariate relationship of distance changing over time. In such graphs, varying the scale of the graph changes the shape of the graphically represented motion, which offers opportunities for students to reason about the relationship between the represented variables and the (qualitative) understanding of slope (e.g., Nemirovsky et al. 2013; Zaslavsky et al. 2002). Even when students are not focusing on numerals and symbols, they can develop graph sense (see, e.g., Krabbendam 1982). This graph sense reflects the ability to look at the represented information at a qualitative global level, becoming sensitive to and focusing on a general trend in the graph itself (Leinhardt et al. 1990). More specifically, graph interpretation on a global scale implies "looking at the entire graph (or parts of it) and gaining meaning about the relationship between the two variables and, in particular, their pattern of co-variation" (Leinhardt et al. 1990, p. 11), whereas graph construction implies the visualization of a certain relationship as representing shapes of trends on the graphs' axes (Matuk et al. 2019).

In summary, graph sense equals the development of a robust understanding enabling a student to overcome most of the difficulties often associated with making sense of graphs. One such difficulty is iconic interpretation of a graph, which occurs when students connect the overall shape of the graph with visual characteristics of the situation represented in the graph. A common example of iconic interpretation would be to interpret a rising line in a distance-time graph as an actual representation of a physical situation such as a car driving up a hill (see, e.g., Clement 1985). Resisting the temptation to interpret a graph by its superficial characteristics might also equate to aspects of critical thinking.

\subsection{Developing graph sense: a 21 st century skill}

The development of graph sense is an important component of 21 st century learning. It includes the skills of interpreting and creating graphs, but also more generally, learning to use flexibly and creatively and evaluate critically graphical representations not earlier encountered, and the ability to apply this understanding in different problem situations. Developing graph sense can be challenging even for university students (e.g., Brasell and Rowe 1993). Nevertheless, younger students already possess the ability to reason with, and construct (graphical) representations of dynamic situations. For example, a study by DiSessa et al. (1991), investigated the ability of students aged 11 to 12 to generate, critique, and refine representational forms. These authors showed how these students developed understanding of different kinds of representations, by drawing graphs of a given motion situation. Here, students started with discrete representations of a motion event before moving on to continuous representations of that motion event. The instructional approach used in this study can be considered as emergent modelling, which implies that students make a specific 'model of' a situation which at a later stage can be used as a 'model for' formal mathematical reasoning (Streefland 1985). For example, students are provided with a task about a particular motion situation for which they have to develop a graphical solution which is situation-specific. The produced graph can be seen as a model of the original motion situation. During this so-called reinvention process, graphs emerge from the students' own activities. When looking at a graph representing different motion situations (or with different represented variables), students can apply their acquired understanding of the graph as a mathematical model of a particular motion situation as a model for reasoning about the represented variables in the graph (Doorman and Gravemeijer 2009). Therefore, students' own inventions (or close approximations), based on experiences with a real-world phenomenon, are a powerful starting point on which to build conventional graphing.

Researchers have often designed tasks involving software environments linking animations and graphs (Roschelle et al. 2000) or motion sensor technology, where a link is forged between a student's own motion and the corresponding graphical representation. Following Mishra and Henriksen 
(2018), taking advantage of such technology is an important aspect of learning in the 21st century, since "technology can powerfully change how and what we teach" (p. 15). For example, students can manipulate specific elements of a graphical representation by means of graphing software. In a fairly easy way, technology can show how zooming in on the graphs' axes might affect the graphical representation of a situation but does not change the situation itself (Godwin and Sutherland 2004). This offers students more opportunities not only to generate, but also refine and critically evaluate graphical representations.

When using motion sensor technology students not only learn to use technological tools but are also stimulated to test their hypotheses about the graphs produced by these tools. Nemirovsky et al. (1998) showed how two students (aged 9 and 10) became fluent tool users when using a computer-based motion detector for creating distance-time graphs of their own movements. Throughout the activities the students developed ways of seeing the graphical representation as a representation of - and as a response to- their bodily actions. Initially, the students experienced how distance-time graphs have some specific idiosyncratic traits (e.g., the line in the graph cannot go backwards), while eventually, the graphical representation became an object they understood and were able to reason with. The use of motion sensor technology has proven to be powerful in offering students a direct experience of their own bodily movement (e.g., Deniz and Dulger 2012; Mokros and Tinker 1987). Through the support of motion sensor technology, students' perceptual-motor experiences are employed to learn graphing conventions (e.g., Arzarello et al. 2007) and thus offer opportunities to connect "the mathematics of change to its historical and familiar roots in experienced motion" (Kaput and Roschelle 2013, p. 20). This linking between a physical experience and the abstraction of that experience as a graph closely aligns with an embodied cognition approach.

\subsection{Embodied cognition}

Embodied cognition theory posits that both concrete and abstract higher-order thinking and reasoning, like language and mathematics, are embedded in sensorimotor schemes that one can acquire through physical interactions of one's body with the environment (see, e.g., Pouw et al. 2014). Hence, learning takes place by enacting knowledge or concepts through bodily activities. This entails that gestural and other bodily activity are fundamental constituents of cognition (e.g., Radford 2009b). When adopting a moderate position towards embodied cognition (Goldman 2012), it is assumed that even when concrete actions and perceptions are not readily available, previously acquired actionperception structures can be simulated, in terms of re-use or re-activation, and may serve the formation of new (abstract) ideas and thoughts (e.g., Barsalou 2010).

\subsubsection{Embodied learning environments}

Following this idea of embodied cognition, developing graphical reasoning has often been investigated in learning environments enriched with direct physical experiences. In these embodied learning environments, bodily experiences are an essential part of the learning activities (e.g., JohnsonGlenberg et al. 2014; Skulmowski and Rey 2018). In the context of graphing motion these bodily experiences can be manifold and range from making whole-, or part-bodily movements, to observing someone, or something else, moving (Duijzer et al. 2019). In some studies, the focus has (inter alia) been on students' use of gestures and their supportive role in expressing ideas and supporting learning graphical reasoning with motion sensor technology (e.g., Radford 2009a, b; Robutti 2006). Radford (2009a, b) focused on the semiotic process in which signs, words, and gestures all work in unison to develop students' graph sense. In particular, the work of a small group of Grade 8 students showed that throughout the graphing activities, including a motion sensor, the students slowly abandoned their iconic interpretation of the graph and reformulated their interpretation in terms of the movements present in the graph (Radford 2009a). Throughout this process students pointed towards characteristics of the graph, data points, lines, and axes. They also made gestures expressing the shape of graphs and indicating motion represented in the graphs (see also, Robutti 2006). Other studies more specifically addressed the role of whole bodily motion in learning activities, for example by looking into how perceptual and motor activities merge when students are engaged in a mathematics activity (Nemirovsky et al. 2013). Similarly, Ferrara (2014) presented two teaching episodes, focusing on a 7-year-old student's perceptual, bodily, and imaginary experiences when walking in front of a motion sensor. This student became able to connect his movements with the graph(s) representing his movements and, a year later, was also able to communicate his understanding of the graph to others.

\section{The current study}

Although the aforementioned studies illustrate the importance of perceptual-motor experiences when reasoning about graphs of motion, they all have a rather laboratory character. These studies presented in-depth analyses of the development of a few students (see, e.g., Nemirovsky et al. 1998; Robutti 2006). It is unclear whether the experiences of those few students could also be elicited in a whole classroom setting, and if so, to what extent this engenders the 
development of higher-order reasoning, and the potential of these activities to stimulate 21 st century skills. In the context of graphing motion we operationalize the 21 st century skills of being creative and thinking critically as students' ability to generate, refine, and evaluate graphical representations as well as making flexible and creative use of representations. Following embodied cognition theory, we assume that students-when interacting with motion sensors and collaborating with their peers-start to reason about the connection between their bodily movements and the representation of those movements as a graph. Thus, developing graph sense might be a fruitful way to integrate 21 st century skills in the mathematics classroom.

Most studies conducted in the primary grades using motion sensor technology focused on instructional activities concerning graph interpretation, for example, interpreting a graph as a response to one's own movements in front of the motion sensor (e.g., Nemirovsky et al. 1998). Moreover, in studies in which students' developing understanding about motion graphs was actually measured, tests often include graph interpretation items, using a multiple-choice format (see, e.g., Deniz and Dulger 2012). Graph sense however, does not contain only graph interpretation, but also graph construction (Friel et al. 2001). Research has shown that students of all ages experience difficulties with both graph interpretation and graph construction. Moreover, the skill to present data and communicate this data to others is vital for many future professions (e.g., Leinhardt et al. 1990). Therefore, it is important that both interpretation and construction skills are addressed in lesson activities, as well as afterwards on lesson-specific tasks, and that students are given the opportunity to show their reasoning when interpreting and constructing graphs.

In the current study, we investigate the development of primary school students' understanding of-and reasoning about-motion graphs in a whole class teaching and learning setting. Our focus is on graphing change in the context of modelling motion. To elicit students' reasoning about motion graphs, we developed an embodied learning environment consisting of a six-lesson teaching sequence. In this embodied learning environment, students made distance-time graphs of their own movements by moving in front of a motion sensor. As such, we expected that students would no longer consider the resulting graphical representation as a standalone, isolated entity, but as a reference to their own bodily experiences. Students were given ample opportunities to reason about the resulting graphical representations-throughout the lessons and afterwards on lesson-specific graph interpretation and graph construction tasks-enabling them to communicate their understanding about the graphs. More specifically, we answer the following research question:
How does students' reasoning about graphing motion develop over a six-lesson teaching sequence within an embodied learning environment?

In answering this research question, we first investigate the development of students' reasoning over the six-lesson teaching sequence by looking at their performance on graph interpretation and graph construction tasks. We then provide an in-depth analysis of how the embodied learning environment might have supported the students in their ability to generate, refine, and reason about graphical representations of motion. For this, we particularly focus on one student and her interactions with the motion sensor technology and her peers.

\section{Method}

\subsection{Participants}

To answer the research question, the teaching sequence was taught in three primary school classes (Grade 5; 9-11 years) in the area of Utrecht, The Netherlands, between October 2016 and June 2017. Only schools sharing similar demographics were contacted. Classes were chosen based on teachers' willingness to participate. Participation was voluntarily. A total of seventy students participated in this study; 28 girls ( $40 \%)$ and 42 boys (60\%) $\left(M_{\text {age }}=10.4, S D=0.45\right)$. For seven students (out of 77) we did not get parental consent to use the data. The research was conducted in accordance with the ethical guidelines of the Institutional Review Board of the faculty of Social and Behavioural Sciences at Utrecht University. All students took part in the teaching sequence as part of their regular classroom instruction.

\subsection{Procedure}

Each lesson took about 50 min and was taught by the first author supported by a teaching assistant. The lessons were given weekly in 6 consecutive weeks. In Lessons 3-5, in the first part of the lessons, the class was split into four small groups to allow students to work individually with the motion sensors. These small groups were supervised by research team members who followed a lesson script in order to ensure implementation fidelity. The small-group activities took $30 \mathrm{~min}$. The remainder of the lessons was given to the entire class. After each lesson, students responded to two lesson-specific tasks: one task related to graph interpretation and the other to graph construction. A repeated measurement design was used: every second task was also provided to the students after the subsequent lesson (i.e., the second task provided after Lesson 1 was the same as the first task after Lesson 2). 
Table 1 Overview of the six-lesson teaching sequence on graphing motion

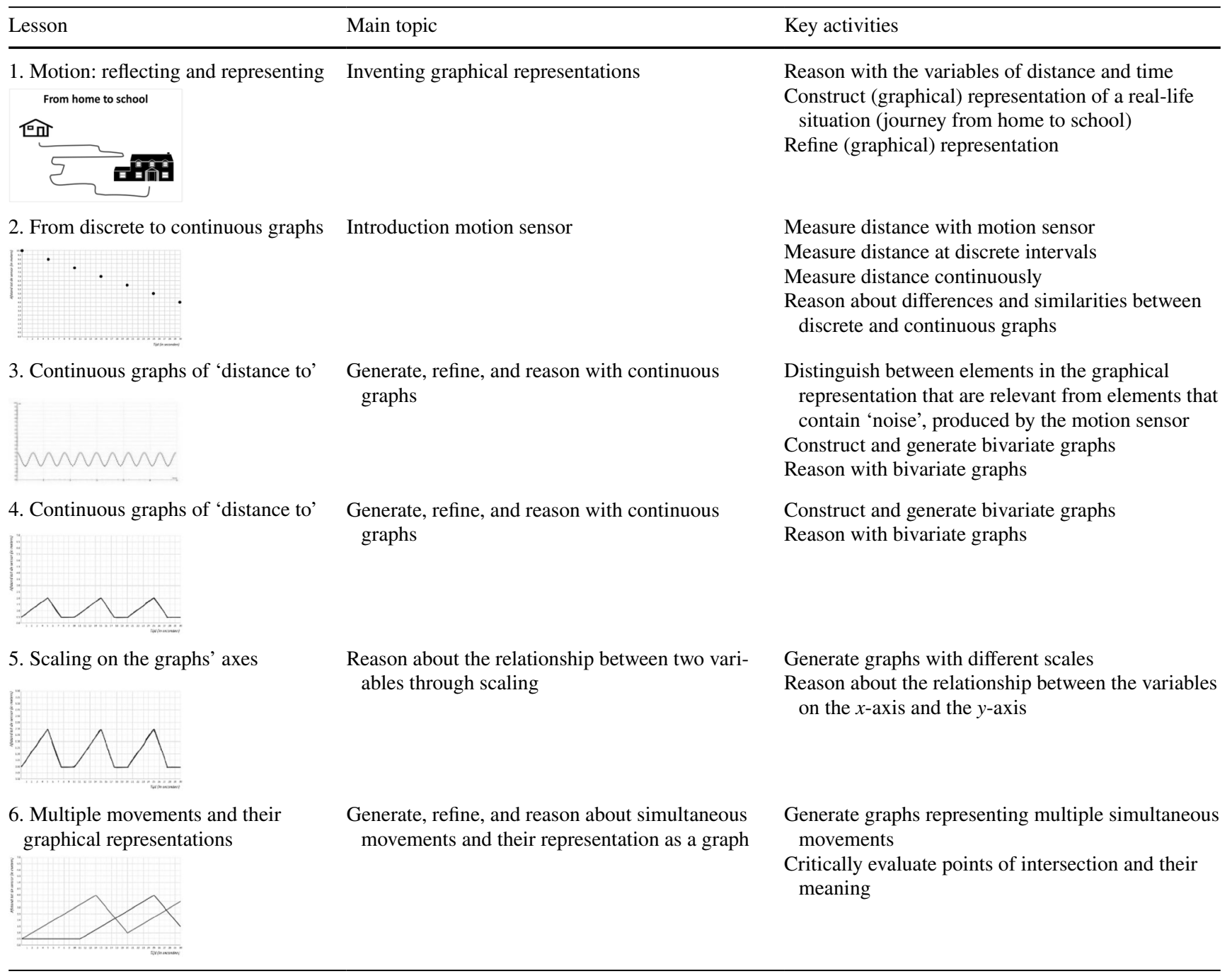

\subsection{Data collection}

We collected data from various sources: videotaped lessons, student material, and student responses to lesson-specific tasks after each lesson. Within one class we videotaped a small group of students $(n=7)$ from whom video permission was obtained. Video sections in which students were engaged with the motion sensor technology were identified and transcribed. We chose to focus mainly on one student, Celine. She showed a progression over the lessons, which was representative for many of the other students. Throughout the lessons Celine showed high motivation, creativity, and attention towards the activities. She was also able to explain her thinking fluently. Based on her score in the mathematics test of the Dutch student monitoring system and the population data of this test (Cito LOVS, Janssen et al. 2010), she can be considered a slightly above average student. We present two teaching episodes, consisting of interactions between Celine and the students with whom she worked.

\subsection{Materials}

\subsubsection{Teaching sequence on graphing motion}

In the first lesson, students developed their own representations of a motion situation. In the following lessons, situations in which distances were measured at particular moments were proposed. Finally, students solved problems by modelling dynamic data and reconstructing events from continuous graphs. The problems or tasks did not explicitly ask them to perform calculations; the required reasoning was mainly global and qualitative (see, e.g., Leinhardt et al. 1990). In particular, the teaching sequence started from informal graphs to working with discrete graphs and finally continuous graphs. During this trajectory the concepts of scaling on the graphs' axes, qualitative understanding of slope, and qualitative methods of graph interpretation and construction were addressed. See Table 1 for an overview 
of the teaching sequence, examples of the types of graphs presented in each lesson, and a description of key activities.

In order to provide an immediate link between the dynamic situation of moving in space and its graphical representation, we used a motion sensor which directly represented the dynamic situation as a distance-time graph. As such, during the lessons, students' embodied experiences of moving in front of the motion sensor played a central role. The motion sensor was used in all lessons except Lesson 1. In Lesson 2 and Lesson 6 most students observed other students who were walking in front of the motion sensor. From Lesson 3 to Lesson 5 all students walked in front of the motion sensor individually. The craggy graphs created by the motion sensor offered students opportunities to reason about and critically reflect on these graphs, to separate essential elements from noise (e.g., neglecting the vertical strokes caused by someone being out of the sensor), and to discuss how these elements relate to the movement in front of the sensor (see Fig. 4). Throughout the lessons the teacher coordinated the small group and classroom discussions by asking open-ended questions such as 'What do you think would happen if...?', 'Why do you think so?', 'Can you think of more ways to achieve a similar result?', 'Do you see a pattern?', thus stimulating students' thinking and argumentation but leaving them free to come up with their own ideas.

\subsubsection{Motion sensor technology}

We made use of two ultrasonic €Motion sensors, developed by CMA, in conjunction with Coach6 Software (Heck et al. 2009). The tool was programmed to provide a single graph in which the distance between the sensor and the nearest object was displayed over a period of $30 \mathrm{~s}$. The graph was projected either on the digital classroom board (Lesson 2 and 6) or on the screen of laptop computers (Lesson 3-5). When a student moved backwards, the distance between the sensor and the student increased, when a student moved forwards, this distance decreased.

\subsubsection{Lesson-specific tasks: graph interpretation and construction}

In the lesson-specific tasks all provided graphs were distance-time graphs (with and without measurement units) describing the motion of a person or object. The graph interpretation tasks consisted of a graph for which the students had to decide whether three different situations or graphs could fit the given graph (see Fig. 1). The graph construction tasks consisted of a description of a motion situation including multiple variables on the basis of which students had to draw a graph representing that situation (see Fig. 2). For each graph interpretation task students also had to answer an open-ended question, which probed them to make their reasoning explicit.

\subsection{Data analysis}

\subsubsection{Coding scheme for students' level of reasoning about graphs}

Students' responses to the lesson-specific tasks were analysed to investigate the development of their level of reasoning over the teaching sequence. These responses and explanations were categorized by means of a coding scheme. The development of this coding scheme occurred in conjunction with the analysis of the qualitative data. First, research team members individually classified the student responses and later these classifications were compared and if necessary revised. After several discussion and revision rounds, we agreed upon having four main codes that enabled us to categorize student responses to the lesson-specific tasks of graph interpretation and graph construction, from less to more sophisticated: unrelated reasoning, iconic reasoning, single variable reasoning, and multiple variable reasoning (for details and examples of these codes, see Table 2). In this categorization, the 21 st century skills of generating, refining, and evaluating graphs are captured by focusing on the extent to which students included the information about the different variables in their reasoning. To validate our categorization into iconic reasoning, single, and multiple variable reasoning, we compared this process to the categories used in several other studies on graphical reasoning. For example, Lingefjärd and Farahani (2017) identified three categories: (1) intuitive and iconic interpretations, (2) scientifically grounded interpretations and (3) a combination with influences from both 1 and 2. Similarly, Johnson et al. (2019) included an iconic category and three other categories: motion of objects, individual quantities, and relationship between quantities. Our categories resemble these earlier categorizations.

The three different graph interpretation tasks were all of similar difficulty: the same type of reasoning led to the correct answer and explanation. In the three graph construction tasks, students had to represent a given situation graphically. The difficulty of these graph construction tasks gradually increased in the sense that the situations students had to model became more complex. We chose this approach because during graph construction, a student has to generate something that is not there yet (Leinhardt et al. 1990). When interpreting a graph, a student has to evaluate and recognize elements that are already apparent. Therefore, our graph interpretation tasks could, from the start, be more complex. 


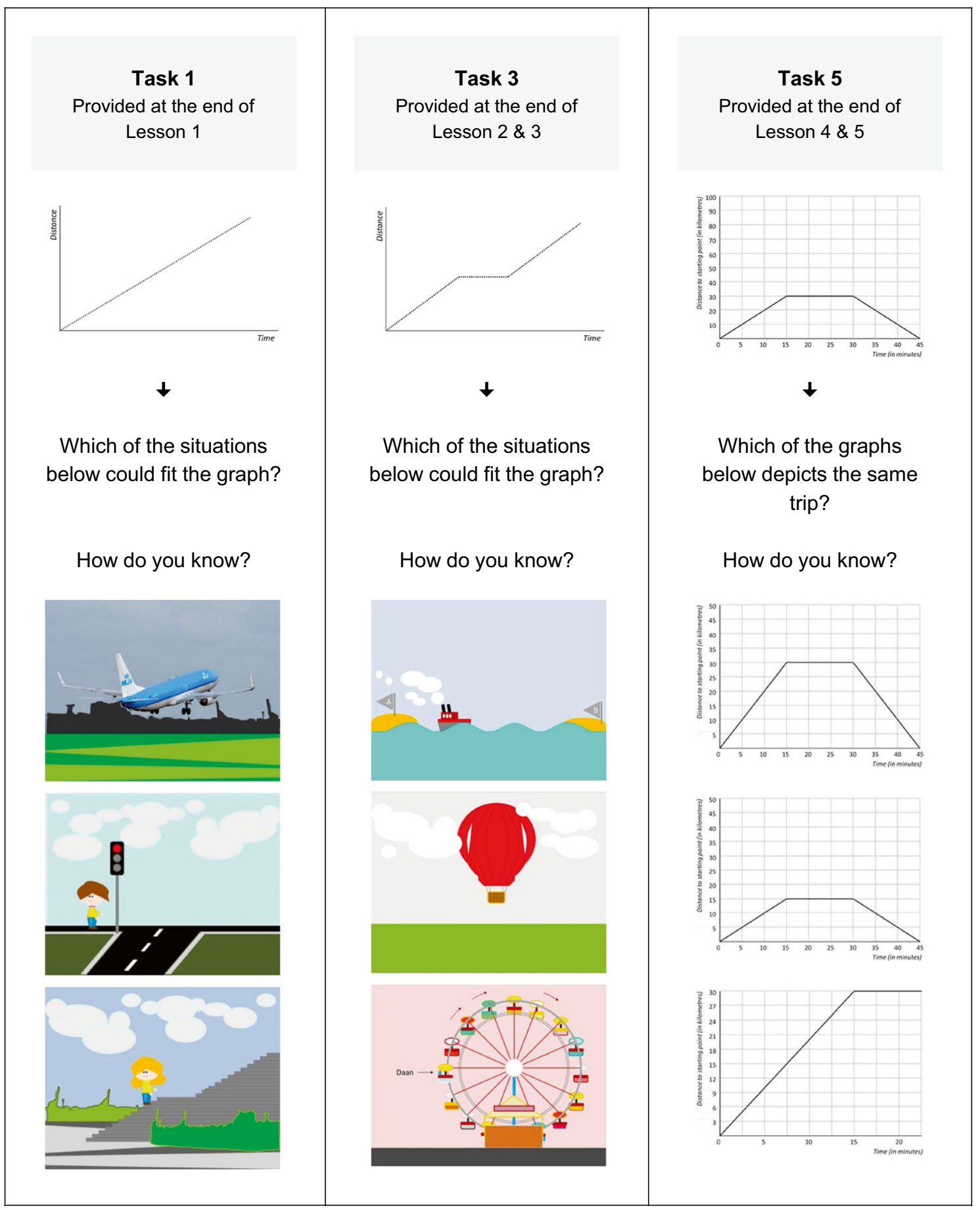

Fig. 1 Lesson-specific graph interpretation tasks

\subsubsection{Teaching episodes}

To investigate how students' perceptual-motor experiences in front of the motion sensor aided their reasoning about the graphical representations, we analysed two teaching episodes in more detail. We focus particularly on Lesson 3 (Episode 1) and Lesson 5 (Episode 2). In these lessons, crucial moments in which the relation between students' experiences and their reasoning in terms of generating, refining, and evaluating graphs were apparent, could be distinguished.

Lesson 3 marks the beginning of the critical evaluation of how motion is represented in a continuous graph. Students encounter situations in which iconic interpretations lead to incorrect conclusions. They experience that particular 


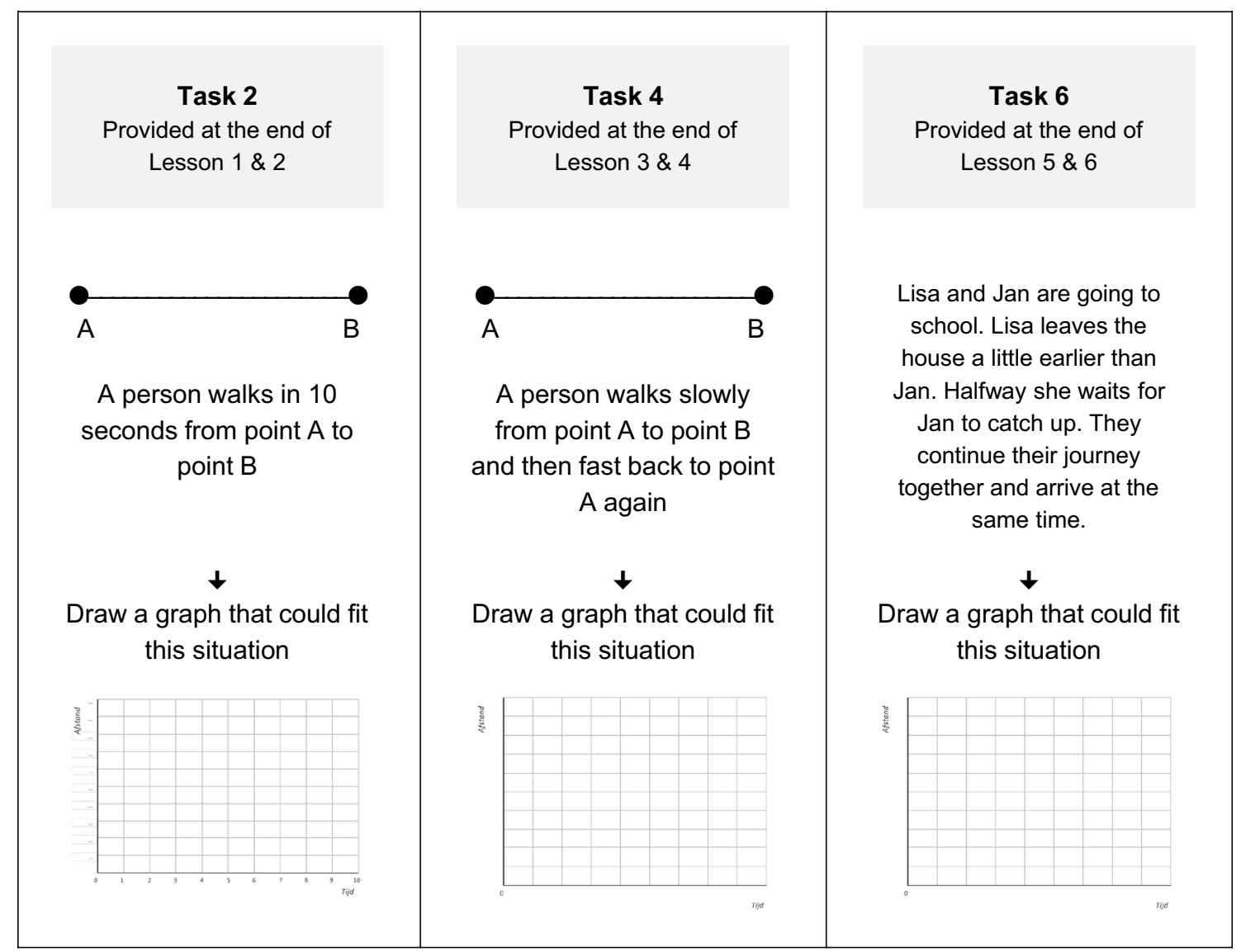

Fig. 2 Lesson-specific graph construction tasks

aspects of movements relate to features of the graph (e.g., relating the direction of a motion to an increasing distance from a given point), which offers opportunities for the students to extend, refine, and develop reasoning by challenging their pre-existing conceptions of motion graphs. In this lesson, students have their first individual experiences in front of the motion sensor.

In Lesson 5 the element of scale is explicitly introduced. Students interpret the shape of the graphs in relation to the graphs' features and connect points in the graph to distance and time values on the axes and to locations in space. Additionally, making the students sensitive to how changes in scale on the graph's axes relate to what the graph will look like, challenges students' critical thinking skills. Again, in Lesson 5, students enact motion in front of the sensor individually.

The two teaching episodes took place in the same class. We zoom in on one particular student, named Celine. At the end of the first and second lesson Celine had shown only instances of iconic reasoning. In our description, we took a micro-analytic approach (see, e.g., Nemirovsky et al. 2013), focusing on Celine's reasoning when interacting with the motion sensor, including her gestures and movements, to get a grasp of her developing understanding. We also describe the actions of her peers, thus showing how she, in interaction with her classmates, comes to correctly interpret the concepts of time, distance, and speed as represented in the graphs.

\section{Results}

\subsection{Students' level of reasoning over the teaching sequence}

Students' answers on the graph interpretation and construction tasks improved over the teaching sequence, as shown by more frequent occurrences of high levels of reasoning (Level R2 and R3) towards the end of the teaching sequence. Figure 3 shows the proportion of students with a particular level of reasoning for both graph interpretation and construction tasks. For Task 1, the lesson-specific task administered after the first lesson, students' reasoning could be qualified as iconic reasoning (Level R1: 55\%), that is to say, reasoning in which the graphical representation was interpreted as an analogous depiction of the represented situation, for 
Table 2 Coding scheme used for students' level of reasoning on the graph interpretation and construction tasks

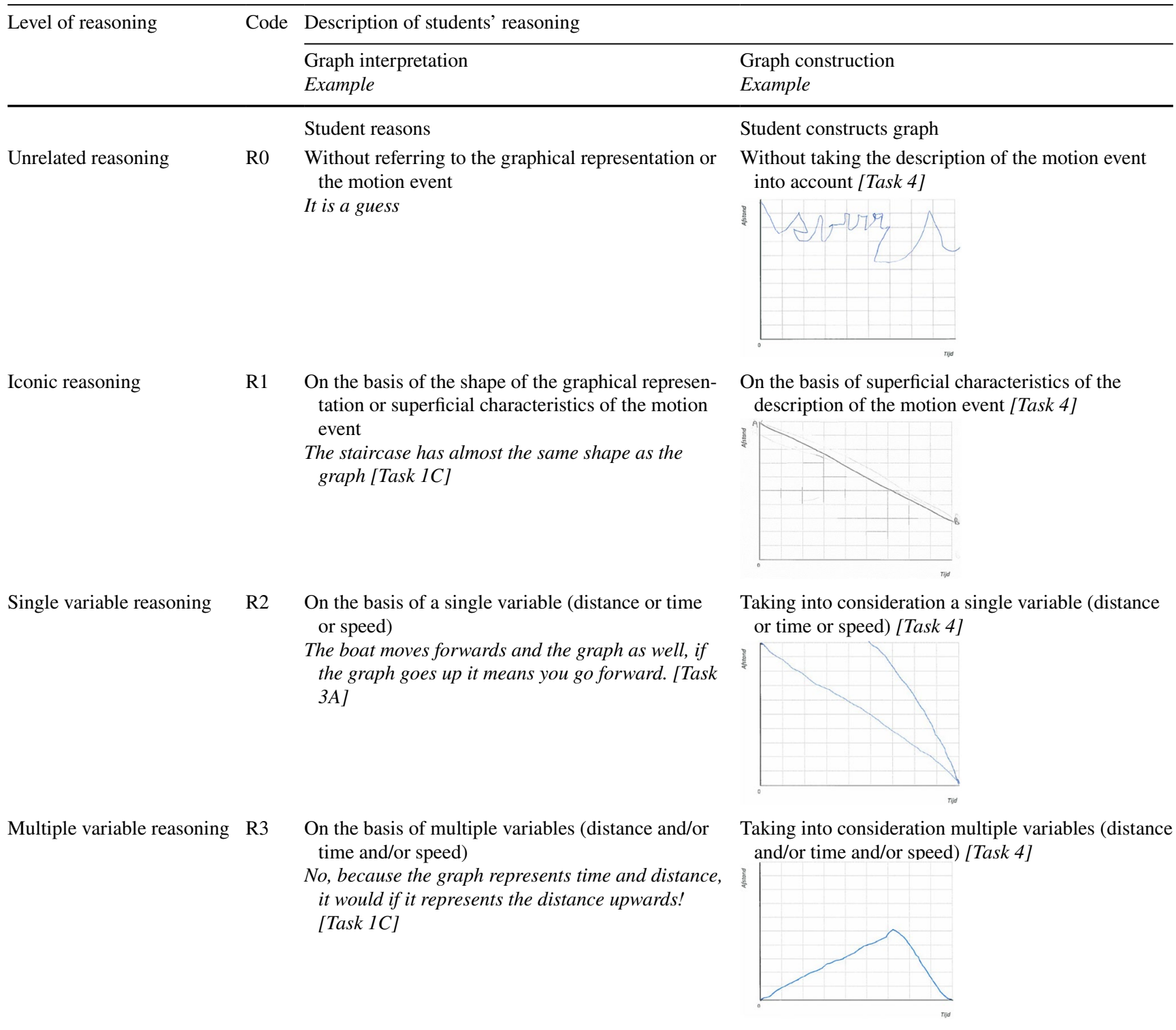

The complete coding scheme, including examples of student responses per task, can be found in the Electronic Supplementary Material of this paper. ESM 1 (graph interpretation) and ESM 2 (graph construction)

example on Task 1A 'In the graph it goes up and here the airplane also goes up'. A smaller proportion of the students reasoned while taking into account a single variable (Level R2: 40\%), for example on Task 1A 'He travels a distance and then he continues', whilst only $3 \%$ of the students showed reasoning in which they referred to the graph as representing a bivariate relationship (Level R3), for example on Task 1A 'Because he travelled a certain amount of distance within a certain amount of time'.

Over the course of the teaching sequence the frequency of students' iconic reasoning on graph interpretation gradually decreased (from about $50 \%$ in Lesson 2-9\% in Lesson 5), whereas the frequency of students' single variable reasoning increased towards the third lesson (from about $46 \%$ in Lesson 2, to $78 \%$ in Lesson 3) and then decreased in Lesson 4 and again slightly increased towards Lesson 5 (62\% in Lesson 4 and 66\% in Lesson 5). Examples of students' single variable reasoning were responses such as 'The distance increases just as with the hot air balloon and this is shown in the graph' (Task 3B) and 'The one in the top is stretched more but there it is 30 kilometre and here as well' (Task 5A). The decline in the frequency of single variable reasoning co-occurred with an increase of the frequency of students' multiple variable reasoning (from less than $7 \%$ in Lessons 


\section{Graph interpretation}

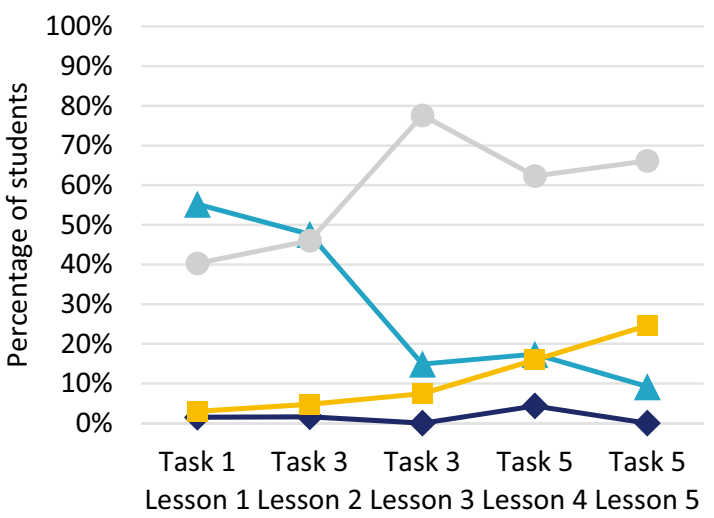

\section{Graph construction}

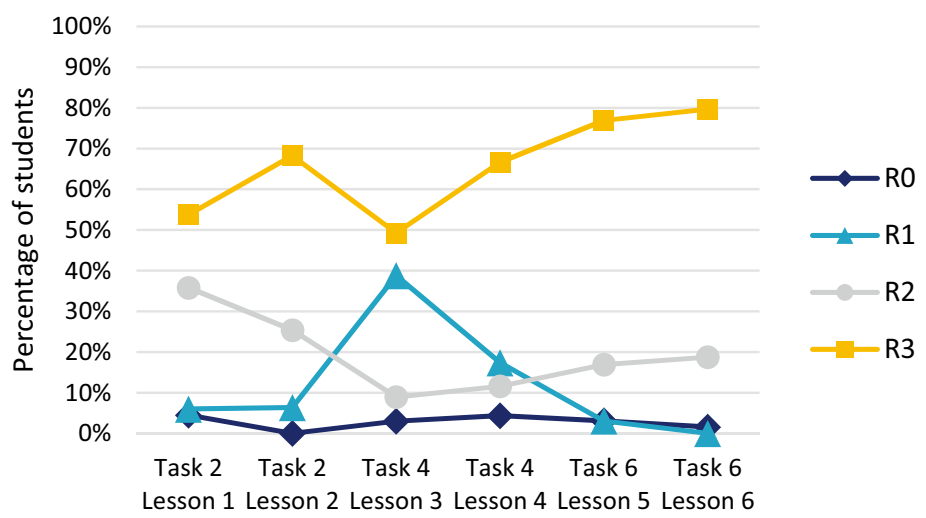

Fig. 3 Students' level of reasoning $\left(N_{\text {Lesson 1 }=67}, N_{\text {Lesson 2 }=63}, N_{\text {Lesson 3 }=67}, N_{\text {Lesson 4=69 }}, N_{\text {Lesson 5=65 }}, N_{\text {Lesson 6=64 }}\right)$

1-3 to $25 \%$ in Lesson 5). An example of such reasoning was 'He moves till 30 kilometres in 15 min, then waits, and after 30 min back again' (Task 5A). Students' reasoning on the graph construction tasks showed a different pattern. From the first lesson onwards most students were able to incorporate at least two variables correctly when creating a graph of a given motion situation. This skill continued to increase towards Lesson 6 (from about 54\% in Lesson 1-78\% in Lesson 6). This increase co-occurred with a gradual decrease on iconic reasoning from Lesson 3 onwards (Level R1: from about 38\% in Lesson 3-0\% in Lesson 6).

\subsection{Perceptual-motor experiences and developing graph skills}

When looking at the changes in students' level of reasoning on the lesson-specific tasks, Lessons 3 and 5 appear to be benchmark lessons. First, for graph interpretation, there were more students who reasoned based on a single variable on Task 3 after Lesson 3 than after Lesson $2(+32 \%)$. In the first teaching episode, we show students' interactions with the motion sensor and related reasoning in the third lesson. Second, from Lesson 4 till 5 (Task 5), there were more students who reasoned based on single variable $(+4 \%)$. Additionally, there were also more students who reasoned in a covariational manner, taking into account multiple variables when interpreting the graph(s) (+ 9\%). For graph construction a similar pattern is shown from Lesson 4 till 5 (R2: + $5 \%, \mathrm{R} 3:+10 \%)$, although these tasks were different and not entirely comparable. During the fifth lesson, students moved in front of the motion sensor individually. Furthermore, during this lesson, more emphasis was placed on the graphs' axes (e.g., focusing on scale and intervals on the $x$-axis and $y$-axis), prompting students to be critical of how a particular scaling on the graph's axes would change its appearance, which Task 5 assessed more explicitly. In Episode 2 we show a short excerpt of an interaction between a few students to show the kind of reasoning during the fifth lesson.

\subsubsection{Episode 1: Walking a given graph}

In Lesson 3, after some exploration of the motion sensor, students had to replicate the distance-time graph depicted in Fig. 4 (left panel). To do this they had to interpret the graph in terms of distance from the sensor, where and when to start and stop, and about time, because each wave takes a certain amount of time.

First, the graph was discussed with the students, then Mark was chosen to walk the graph. Initially, Mark walked faster than the graph required. Amir and Celine discussed Mark's movements and what they thought he should change. The graph walked by Mark showed fewer curves than the given graph in the same time-interval, while covering more distance.

1. Celine: He is making them bigger. [Gestures the shape

2. of the curve Mark is walking ]

3. Celine: They have to be closer together

4. Teacher: How could we make the graphs more similar?

5. Celine: A little faster... and a slightly shorter distance?

While Mark was walking the graph, it became clear that his graph was not entirely similar to the given graph. Celine noticed that Mark's waves were larger than the ones in the given graph. He covered more distance, while it also took him longer to make each curve. In sharing her ideas, she used gestures to describe the shape of the graph (Lines 1-2). Initially, Celine did not describe the wave shape of the graph verbally, but her gesture clarified what she meant. She corroborated this gesture when she said 'they have to be closer together' (Line 3). Celine shared specific ideas about the movements associated with a certain shape in the graph. She further mentioned that someone should walk 'a 

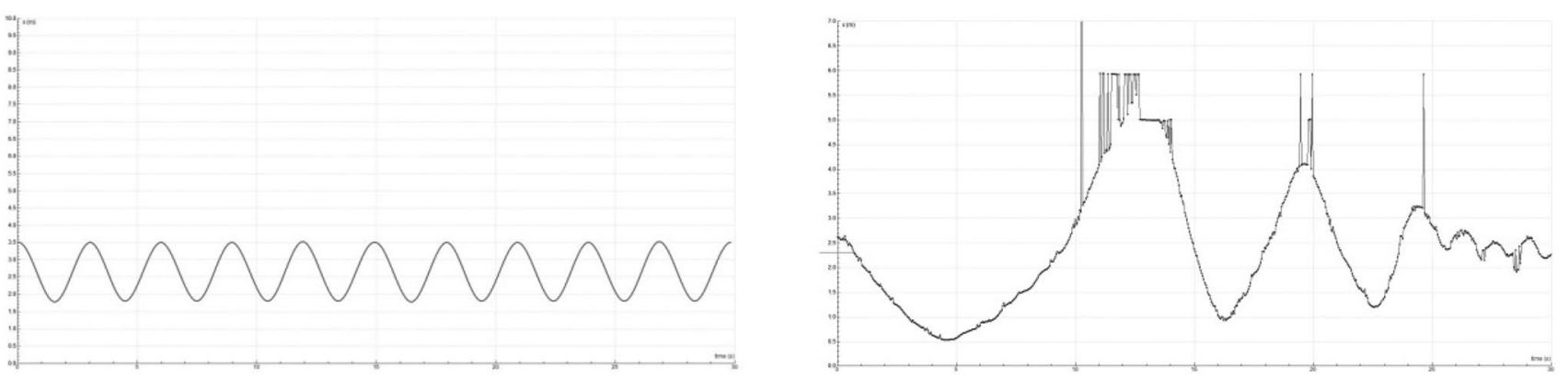

Fig. 4 Given graph of back-and-forth movement in front of the motion sensor (left panel) and a graph produced by a student (right panel)

little faster' covering a 'slightly shorter distance' (Line 5). Celine's interpretation includes the variables time and distance in a covariational manner. Her reasoning, considering both time and distance, and combining them with speed, was prompted by her observation of Mark's movements in front of the sensor.

This is an example of how technology can be used to our advantage in strengthening the domain-specific 21 st century skills of generating, refining, and evaluating graphical representations. The technology and the activity allowed the students to look critically at what went on in the graphical representation, when desired results were absent. Words and gestures helped the students to connect the shape of the graph (e.g., concavity of the curve) to the movements needed to reproduce the graphs (e.g., walking faster). Moreover, the students became increasingly able to communicate the relational aspect of the variables distance and time, when interpreting and describing the graphs. Celine's reasoning shows how the embodied learning environment prompted students to move beyond iconic interpretations of the graph, illustrated by some students who initially started to jump in front of the sensor. The graph that Mark walked, prompted Celine to pose a specific hypothesis, showing that Celine was very well able to describe in words what should be changed in the situation in order to change the appearance of the graph. This was rather exemplary; over the course of the lesson students became increasingly able to distinguish between relevant and irrelevant movements, and between relevant and irrelevant parts of the graph. The students became aware of the graphs' shape at a global level (a curve, possible and impossible shapes).

\subsubsection{Episode 2: Experiencing that speed matters}

In Lesson 5, students' interpretation of the scale on the graph's vertical axis was explicitly addressed. At the start of this episode the teacher asked what motion was represented by the graph on the left in Fig. 5. After a short discussion, the students reached the conclusion that someone should walk slowly away from the sensor, then fast towards the sensor, and finally stand still, while performing this sequence three times in total.

Vanessa was chosen to walk the graph. First, the students discussed from where to start walking. This required them to connect a specific point in the graph to a specific position in the classroom, considering that the graph describes the distance from the sensor, represented on the vertical axis. Then, the teacher activated the sensor. Vanessa started walking the graph, first walking backwards, then forwards, standing still, and walking backwards again. All students paid close attention to her movements and the graph on the screen of
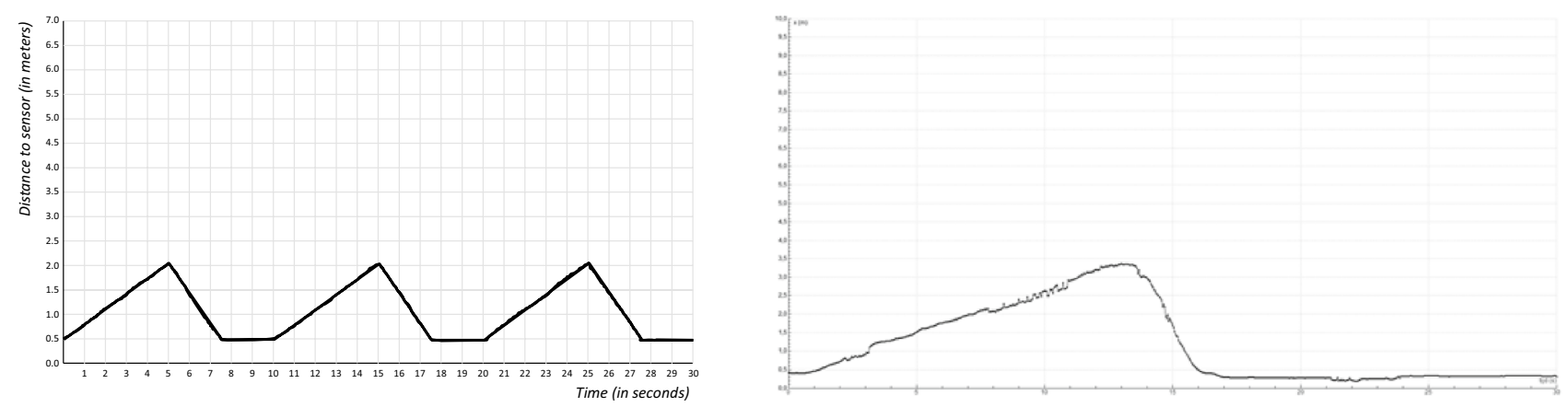

Fig. 5 Given graph (left) and a graph (right) produced by a student by moving in front of the motion sensor 
the computer. Initially, Vanessa walked away and towards the sensor at a constant speed.

6. Celine: Now, walk faster forwards again. [Raises her

7. arm, gesturing Vanessa to walk faster towards the

8. sensor, indicating in her gesture an increase in speed

9. gestures several times very quickly]

10. [Vanessa walks towards the sensor, stands still,

11. and walks backwards]

12. Celine: Slowly backwards and then fast forwards.

13. [Repeats the gestures she just made, urging Vanessa

14. to walk faster towards the sensor ]

Immediately hereafter, Vanessa walked towards the sensor a little faster than she did before. After this, the resulting graph on the screen was compared with the given graph. A short discussion unfolded about the aspects that differed between the two graphs. The highest point in the graph just walked by Vanessa did not match the given graph.

15. Teacher: How high is the highest point here [Points

16. towards the graph ]

17. Celine: Two meters, so... [Takes one large step back-

18. wards, and another large step backwards ] ...over here.

Even though the teacher discussed the graph and the different paces of walking with the students beforehand, Vanessa did not yet incorporate this in her walking. Celine, however, seemed to understand that in order to make the graph similar to the given graph, Vanessa should walk faster towards the sensor than when walking away from it. In order to communicate her ideas, Celine resorted to the use of metaphoric-representational gestures, enacting Vanessa's walk. With her gestures, she explicated how Vanessa should walk faster, as if she were conducting the movement herself, corroborating it by saying 'walk faster forwards again' (Line 6).

Furthermore, as shown in the second half of the interaction, for Celine it was self-evident that, when walking towards a specific point, the vertical axis conveys positional information of the variable distance (Line 17-18). This understanding is indicated by Celine's walking while saying 'two meters, so...' (Line 17) and '...over here' (Line 18), which can be interpreted as deictic signs, showing where someone should be according to the highest point in the graph. This seems to be an important step in the development of Celine's reasoning. By using 'here' (Line 18), to denote this point, Celine is explicitly linking the position in the graph to a position in walking space, even without having the direct feedback of the motion sensor. Throughout the activity she shows her ability to deploy the 21 st century skills of flexibly and creatively using the graphical representation and relate the representation to the real-world situation it represents.
Moreover, the link made by Celine is quantitative, making two large steps, indicating the first and the second meter.

\section{Discussion}

By offering students opportunities to interpret and create graphical representations of motion, this study proposed a domainspecific operationalization of the 21 st century skills of using graphs to produce, present, and understand complex dynamic information. Students participated in activities that were situated in an embodied learning environment in which they were asked to interpret, create, change, combine, and compare graphical representations of their own and other's motion.

\subsection{Students' development in levels of reasoning on graph interpretation and graph construction}

Based on our analyses of students' level of reasoning, at the beginning of the lessons, students' graph interpretation skills were relatively weak. Students were inclined to interpret a graph as a literal depiction of the situation, which was also found in previous research investigating students' graph interpretation skills (e.g., Clement 1985; Mokros and Tinker 1987). These iconic interpretations were quite persistent in students. Even after students were introduced to graphs describing distance-time relationships (from Lesson 2 onwards) iconic reasoning was still the most prominent level of reasoning on graph interpretation tasks. Only after Lesson 3 , which was the first lesson in which students enacted motion in front of the motion sensor individually, which provided them with opportunities to generate, refine, and critically evaluate motion graphs, the iconic level of reasoning became less common. For the graph construction tasks students also improved over the lessons, showing an increase in students' answers including higher levels of reasoning towards the end of the lesson series, despite the fact that the motion situations students had to model became more complex. From the third lesson onwards students rarely constructed iconic graphs, whereas they often drew graphs in which more than one variable was correctly taken into account.

Overall, we found that multiple variable reasoning was more often present in students' answers on the graph construction than on the graph interpretation tasks, which more often included single variable reasoning. According to Leinhardt et al. (1990) graph construction is more complex than graph interpretation because "interpretation relies on and requires reaction to a given piece of data (e.g., a graph, an equation, or a data set) [whereas] construction requires generating new parts that are not given" (Leinhardt et al. 1990, p. 12). Berg and Smith (1994) conjectured how graph construction tasks might force students to consider both local and global aspects of graph construction which leads to higher-levels of cognitive 
engagement. They contrast this with graph interpretation tasks in which students do not have to consider local aspects of the graph and more often choose a graph that fits the picture of the situation, in an iconic way. This is consistent with our results. For example, in Lesson 1, when comparing students' reasoning on Task 1 and Task 2, both with the same graph, they more often showed iconic interpretations on the graph interpretation task and more multiple variable reasoning on the graph construction task. In our study, students reached high levels of reasoning when constructing graphs of motion, taking into account various aspects of distance-time relations present in the motion situations. This might indicate that the graph construction tasks challenged the students to deploy high levels of cognitive engagement, illustrating the usefulness of such tasks for higher-order thinking activities, in line with the intended 21 st century skills of interpreting and creating graphical representations.

\subsection{The role of perceptual-motor experiences in developing graphing skills}

Over the two episodes Celine's reasoning went from iconic interpretations towards covariational interpretations (i.e., distance changing over time) (see Radford 2009a). The first episode focused on students' modelling of motion represented in a given graph by moving in front of the motion sensor individually. Celine incorporated signs, words, and gestures to come to a deeper understanding of graphically represented motion (see also Radford 2009a), by coordinating the (observed) motion with the graphical representation on the screen. For example, Celine made use of iconic representational gestures (Roth 2001). Botzer and Yerushalmy (2008) argue how such gestures imply that Celine mentally stretched the graph in order to compare it with the original one, thus revealing her perceptual-motor and analytical thinking (see, e.g. Robutti 2006). The second episode introduced speed more explicitly, noticeable in the steepness of slope as a result of walking at varying speeds in front of the sensor. In both Vanessa's and Celine's reasoning, moving, and gesturing, the concept of speed was apparent (see also Radford 2014).

\subsection{Limitations of the study}

There are some limitations to the current study. First, this study is based only on students in three classes. Including more classes would enhance the robustness of our findings. Second, in order to show students' development over time we primarily focused on students' writing on the lessonspecific tasks and we illustrated how this reasoning was elicited during the lessons in the teaching episodes. According to Radford et al. (2004) "a direct translation of actions into symbols require[s] the students to undergo a dynamic process of imagining, interpreting and reinterpreting" (p. 73).
More research is necessary to establish how students' physical experiences in the lessons relate to their answers on the lesson-specific tasks students performed on paper. For example, to what extent do students use their experiences of moving in front of the motion sensor? A research methodology with think-aloud protocols when solving the lesson-specific tasks might be suitable. A third, related limitation is that students' reasoning on the lesson-specific interpretation tasks might not be a precise reflection of their understanding. It could be that they did not write down their entire reasoning. We observed students' reasoning in a covariational manner throughout the lessons but did not see this level of reasoning in their answers to the lesson-specific graph interpretation tasks. In that sense, the results for the graph interpretation tasks might underestimate their full understanding, which provides another explanation for the limited occurrence of multiple variable reasoning on these tasks.

\subsection{Concluding remarks}

This study contributes to theories of mathematical thinking and learning by showing how embodied activities engender high levels of mathematical reasoning. As such, our study was an extension of previous research that showed the capability of students this age to model dynamic data and reason about the relationship between multiple variables, when engaging in their own immediate motion learning activities. Experiences in primary grades do not usually provide children the opportunity to engage in mathematics and science activities that involve modelling motion. We found that embodied activities using technology can be applied in an authentic and realizable classroom setting (see also, Deniz and Dulger 2012). As opposed to previous studies incorporating graphing activities, we asked students to also create graphs instead of only interpret given graphs. The lesson-specific tasks used in our study were fit to capture the intended domain-specific 21 st century skills of generating, refining, and evaluating (motion) graphs. We saw a gradual decrease in the occurrence of iconic reasoning over the lessons while higher levels of reasoning (i.e., reasoning with a single variable or multiple variables) were more noticeable towards the end of the lessons. Students' thinking about these graphs went beyond merely replicating factual information and can be considered, for students at this age, as higher-order thinking. Students' perceptual-motor experiences in front of the motion sensor seemed to have been crucial in achieving this result. The activities allowed them to reason about and critically evaluate graphical representations while using their creative thinking skills in adjusting their movements in order to replicate graphs more closely. This illustrates the potential of a sequence of embodied, constructive and reflective activities using technology. 
Acknowledgements This research was supported by Grant 405-14-303 from The Netherlands Initiative for Education Research (NRO) for the Beyond Flatland project. We would like to thank the students, teachers and the schools for their participation in this study.

Open Access This article is distributed under the terms of the Creative Commons Attribution 4.0 International License (http://creativeco mmons.org/licenses/by/4.0/), which permits unrestricted use, distribution, and reproduction in any medium, provided you give appropriate credit to the original author(s) and the source, provide a link to the Creative Commons license, and indicate if changes were made.

\section{References}

Arcavi, A. (1994). Symbol sense: Informal sense-making in formal mathematics. For the Learning of Mathematics, 14(3), 24-35.

Arzarello, F., Pezzi, G., \& Robutti, O. (2007). Modelling body motion: An approach to functions using measuring instruments. In W. Blum, P. L. Galbraith, H. W. Henn, \& M. Niss (Eds.), Modelling and applications in mathematics education (pp. 129-136). Boston, MA: Springer.

Barsalou, L. W. (2010). Grounded cognition: Past, present, and future. Topics in Cognitive Science, 2, 716-724. https://doi.org/10.111 1/j.1756-8765.2010.01115.x.

Berg, C. A., \& Smith, P. (1994). Assessing students' abilities to construct and interpret line graphs: Disparities between multiplechoice and free-response instruments. Science Education, 78, 527-554. https://doi.org/10.1002/sce.3730780602.

Binkley, M., Erstad, O., Herman, J., Raizen, S., Ripley, M., MillerRicci, M., et al. (2012). Defining twenty-first century skills. In P. Griffin, B. McGaw, \& E. Care (Eds.), Assessment and teaching of 21 st century skills (pp. 17-66). Dordrecht: Springer.

Boote, S. K. (2014). Assessing and understanding line graph interpretations using a scoring rubric of organized cited factors. Journal of Science Teacher Education, 25, 333-354. https://doi.org/10.1007/ s10972-012-9318-8.

Botzer, G., \& Yerushalmy, M. (2008). Embodied semiotic activities and their role in the construction of mathematical meaning of motion graphs. International Journal of Computers for Mathematical Learning, 13, 111-134. https://doi.org/10.1007/s1075 8-008-9133-7.

Brasell, H. M., \& Rowe, M. B. (1993). Graphing skills among high school students. School Science and Mathematics, 93, 63-70. https://doi.org/10.1111/j.1949-8594.1993.tb12196.x.

Clement, J. (1985). Misconceptions in graphing. In L. Streefland (Ed.), Proceedings of the ninth international conference for the psychology of mathematics education (pp. 369-375). Utrecht: Utrecht University.

Deniz, H., \& Dulger, M. F. (2012). Supporting fourth graders' ability to interpret graphs through real-time graphing technology: A preliminary study. Journal of Science Education and Technology, 21, 652-660. https://doi.org/10.1007/s10956-011-9354-8.

diSessa, A., Hammer, D., Sherin, B., \& Kolpakowski, T. (1991). Inventing graphing: Meta-representational expertise in children. Journal of Mathematical Behavior, 10(2), 117-160.

Doorman, L. M., \& Gravemeijer, K. P. E. (2009). Emergent modeling: Discrete graphs to support the understanding of change and velocity. ZDM-The International Journal on Mathematics Education, 41, 199-211. https://doi.org/10.1007/s11858-008-0130-z.

Duijzer, C., Van den Heuvel-Panhuizen, M., Veldhuis, M., Doorman, M., \& Leseman, P. (2019). Embodied learning environments for graphing change: A systematic literature review. Educational Psychology Review. https://doi.org/10.1007/s10648-019-09471-7.
English, L. D. (2016). STEM education K-12: perspectives on integration. International Journal of STEM Education. https://doi. org/10.1186/s40594-016-0036-1.

Ferrara, F. (2014). How multimodality works in mathematical activity: Young children graphing motion. International Journal of Science and Mathematics Education. https://doi.org/10.1007/s1076 3-013-9438-4.

Friel, S. N., Curcio, F. R., \& Bright, G. W. (2001). Making sense of graphs: Critical factors influencing comprehension and instructional implications. Journal for Research in Mathematics Education, 32, 124-158. https://doi.org/10.2307/749671.

Godwin, S., \& Sutherland, R. (2004). Whole-class technology for learning mathematics: the case of functions and graphs. Education, Communication \& Information, 4(1), 131-152. https://doi. org/10.1080/1463631042000210953.

Goldman, A. I. (2012). A moderate approach to embodied cognitive science. Review of Philosophy and Psychology, 3(1), 71-88. https ://doi.org/10.1007/s13164-012-0089-0.

Heck, A., Kędzierska, E., \& Ellermeijer, T. (2009). Design and implementation of an integrated working environment for doing mathematics and science. Journal of Computers in Mathematics and Science Teaching, 28(2), 147-161.

Honey, M., Pearson, G., \& Schweingruber, A. (2014). STEM integration in K-12 education: Status, prospects, and an agenda for research. Washington, DC: National Academies Press.

Janssen, J., Verhelst, N., Engelen, R., \& Scheltens, F. (2010). Wetenschappelijke verantwoording van de toetsen LOVS RekenenWiskunde voor groep 3 tot en met 8. Arnhem: Cito.

Johnson, H. L., McClintock, E., \& Gardner, A. (2019). Leveraging difference to promote students' conceptions of graphs as representing relationships between quantities. In U. T. Jankvist, M. van den Heuvel-Panhuizen, \& M. Veldhuis (Eds.), Proceedings of the eleventh congress of the european society for research in mathematics education. Utrecht: Freudenthal Group \& Freudenthal Institute, Utrecht University and ERME.

Johnson-Glenberg, M. C., Birchfield, D. A., Tolentino, L., \& Koziupa, T. (2014). Collaborative embodied learning in mixed reality motion-capture environments: Two science studies. Journal of Educational Psychology, 106(1), 86-104. https://doi.org/10.1037/ a0034008.

Kaput, J. J., \& Roschelle, J. (2013). The mathematics of change and variation from a millennial perspective: New content, new context. In S. J. Hegedus \& J. Roschelle (Eds.), The SimCalc vision and contributions (pp. 13-26). Dordrecht: Springer.

Krabbendam, H. (1982). The non-qualitative way of describing relations and the role of graphs: Some experiments. In G. Van Barnveld \& H. Krabbendam (Eds.), Conference on functions (pp. 125-146). Enschede: Foundation for Curriculum Development.

Leinhardt, G., Zaslavsky, O., \& Stein, M. K. (1990). Functions, graphs, and graphing: Tasks, learning, and teaching. Review of Educational Research, 60, 1-64. https://doi.org/10.3102/0034654306 0001001.

Lingefjärd, T., \& Farahani, D. (2017). The elusive slope. International Journal of Science and Mathematics Education. https://doi. org/10.1007/s10763-017-9811-9.

Matuk, C., Zhang, J., Uk, I., \& Linn, M. C. (2019). Qualitative graphing in an authentic inquiry context: How construction and critique help middle school students to reason about cancer. Journal of Research in Science Teaching. https://doi.org/10.1002/tea.21533.

Mishra, P., \& Henriksen, D. (2018). Creativity, technology \& education: Exploring their convergence. Cham: Springer.

Mokros, J. R., \& Tinker, R. F. (1987). The impact of microcomputer-based labs on children's ability to interpret graphs. Journal of Research in Science Teaching, 24, 369-383. https://doi. org/10.1002/tea.3660240408. 
National Council of Teachers of Mathematics. (2000). Principles and standards for school mathematics. Reston: NCTM.

Nemirovsky, R., Kelton, M. L., \& Rhodehamel, B. (2013). Playing mathematical instruments: Emerging perceptuomotor integration with an interactive mathematics exhibit. Journal for Research in Mathematics Education, 44, 372-415. https://doi.org/10.5951/ jresematheduc.44.2.0372.

Nemirovsky, R., Tierney, C., \& Wright, T. (1998). Body motion and graphing. Cognition and Instruction, 16, 119-172. https://doi. org/10.1207/s1532690xci1602_1.

Pouw, W. T., Van Gog, T., \& Paas, F. (2014). An embedded and embodied cognition review of instructional manipulatives. Educational Psychology Review, 26, 51-72. https://doi.org/10.1007/s1064 8-014-9255-5.

Radford, L. (2009a). "No! He starts walking backwards!”: interpreting motion graphs and the question of space, place and distance. ZDM-The International Journal on Mathematics Education, 41, 467-480. https://doi.org/10.1007/s11858-009-0173-9.

Radford, L. (2009b). Why do gestures matter? Sensuous cognition and the palpability of mathematical meanings. Educational Studies in Mathematics, 70, 111-126. https://doi.org/10.1007/s1064 9-008-9127-3.

Radford, L. (2014). Towards an embodied, cultural, and material conception of mathematics cognition. ZDM-The International Journal on Mathematics Education, 46, 349-361. https://doi. org/10.1007/s11858-014-0591-1.

Radford, L., Cerulli, M., Demers, S., \& Guzman, J. (2004). The sensual and the conceptual: Artifact mediated kinesthetic actions and semiotic activity. In M. J. Hoines \& A. B. Fuglestad (Eds.), Proceedings of the 28 conference of the international group for the psychology of mathematics education (pp. 73-80). Bergen: Bergen University College.

Resnick, L. B. (1989). Developing mathematical knowledge. American Psychologist, 44, 162-169. https://doi. org/10.1037/0003-066X.44.2.162.
Robutti, O. (2006). Motion, technology, gestures in interpreting graphs. International Journal for Technology in Mathematics Education, 13(3), 117-125.

Roschelle, J., Kaput, J., \& Stroup, W. (2000). SimCalc: Accelerating student engagement with the mathematics of change. In M. J. Jacobsen \& R. B. Kozma (Eds.), Learning the sciences of the 21st century: Research, design, and implementing advanced technology learning environments (pp. 1-43). Hillsdale: Earlbaum.

Roth, W. M. (2001). Gestures: Their role in teaching and learning. Review of Educational Research, 71, 365-392. https://doi. org/10.3102/00346543071003365.

Schoenfeld, A. H. (2016). An introduction to the teaching for robust understanding (TRU) framework. Resource document. Berkeley: Graduate School of Education, Retrieved 5 April 2017 from http:// map.mathshell.org/trumath/intro_to_tru_20161223.pdf.

Skulmowski, A., \& Rey, G. D. (2018). Embodied learning: Introducing a taxonomy based on bodily engagement and task integration. Cognitive Research: Principles and Implications, 3(6), 1-10. https ://doi.org/10.1186/s41235-018-0092-9.

Streefland, L. (1985). Wiskunde als activiteit en de realiteit als bron [Mathematics as an activity and the reality as a source]. Tijdschrift voor Nederlands Wiskundeonderwijs (Nieuwe Wiskrant), $5(1), 60-67$.

Zaslavsky, O., Sela, H., \& Leron, U. (2002). Being sloppy about slope: The effect of changing the scale. Educational Studies in Mathematics, 49(1), 119-140. https://doi.org/10.1023/A:1016093305 002.

Publisher's Note Springer Nature remains neutral with regard to jurisdictional claims in published maps and institutional affiliations. 